\title{
Erratum
}

\section{Parentifizierung in der Kindheit und psychische Störungen im Erwachsenenalter}

Katarzyna Schier, Ulrich Egle, Ralf Nickel, Bernd Kappis, Max Herke, Jochen Hardt

Psychother Psych Med 2011; DOI: 10.1055/s-0031-1277188

In Abbildung 2i und 2j wurden die Bezeichnungen vertauscht. Der linke Punkt steht jeweils für „kein Missbrauch“, der rechte für „Missbrauch“. Tabelle 2 zeigt nur die Ergebnisse der Regressionsanalysen zur Zielgröße Depression.

Die weiteren Regressionsanalysen können vom Letztautor bezogen werden. 